\title{
LA DELIMITACIÓN DEL DERECHO DE SUFRAGIO ACTIVO POR EL TRIBUNAL EUROPEO DE DERECHOS HUMANOS
}

M. ${ }^{a}$ REYES PÉREZ ALBERDI 
SUMARIO

I. INTRODUCCIÓN. II. EL CARÁCTER INTERESTATAL DEL ARTÍCULO 3 DEL PROTOCOLO I Y LA DEFINICIÓN DE LAS FACULTADES SUBJETIVAS QUE INTEGRAN EL CONTENIDO DEL DERECHO. III. EL SUFRAGIO UNIVERSAL. IV. EL VOTO LIBRE. V. LA IGUALDAD DE VOTO. VI. CONDICIONES OBJETIVAS DE EJERCICIO DEL SUFRAGIO ACTIVO. VII. CONCLUSIÓN. BIBLIOGRAFÍA. 


\title{
LA DELIMITACIÓN DEL DERECHO DE SUFRAGIO ACTIVO POR EL TRIBUNAL EUROPEO DE DERECHOS HUMANOS
}

\author{
M. ${ }^{a}$ REYES PÉREZ ALBERDI \\ mrperalb@upo.es \\ Profesora Ayudante Doctora \\ Universidad Pablo de Olavide, de Sevilla
}

\section{INTRODUCCIÓN}

Con los derechos de participación política se protege la participación democrática de los miembros de la comunidad política en la formación de la voluntad del Estado (o lo que es lo mismo, la autodeterminación de los individuos que se encuentran sujetos al ordenamiento jurídico en la definición de ese mismo ordenamiento) que se articula fundamentalmente a través del derecho de sufragio. Precisamente por ello, el contenido de este derecho no puede quedar reducido al mero acto de la elección, es decir, al ejercicio del voto sino que, por el contrario, se encuentra dirigido a que la voluntad de los ciudadanos se convierta en la voluntad del Estado. Dicho de otra forma, el principio democrático exige que el procedimiento electoral estructure la participación política de modo tal que la futura voluntad popular que se imputa al Estado a través de los órganos representativos sea lo más fiel posible a la voluntad de los ciudadanos expresada en las urnas $^{1}$, lo que conlleva rodear al ejercicio del voto de toda una serie de garantías.

Cfr. BASTIDA FREIJEDO, F. J. (1991): «Elecciones y Estado democrático de derecho» en Revista Española de Derecho Constitucional, núm. 32, págs. 115-134. La cita está tomada de las páginas 129 in fine-130. 
Este es, precisamente, el contenido del artículo 3 del Protocolo I del Convenio Europeo de Derechos Humanos, en el que se establece la obligación de los Estados que lo han suscrito de «organizar, a intervalos razonables, elecciones libres con escrutinio secreto, en condiciones que garanticen la libre expresión de la opinión del pueblo en la elección del cuerpo legislativo².

En la interpretación de este precepto, por tanto, no pueden obviarse las referencias que en el propio Preámbulo del Convenio se establecen a la democracia como elemento basilar del sistema de protección de derechos fundamentales ${ }^{3}$. Igualmente, en la concepción del Tribunal Europeo e Derechos Humanos, democracia, derechos fundamentales y Convenio no pueden separarse, hasta el punto de que, en sus decisiones, se considera a la democracia como un rasgo fundamental del orden público europeo y como el único modelo político compatible con el propio Convenio. Y, precisamente, lo que caracteriza a ese régimen democrático es la celebración de elecciones periódicas que permitan la libre expresión del pueblo en elecciones periódicas a través del sufragio universal.

Nos proponemos en este trabajo analizar la jurisprudencia del Tribunal Europeo de derechos humanos sobre el derecho de sufragio. Sin embargo, no nos va a interesar únicamente la dimensión subjetiva que define la posición jurídica de los ciudadanos en su relación con los poderes públicos y se concreta en los principios de sufragio universal, libre e igual, sino también su dimensión objetiva en tanto que elemento estructural del Estado Democrático, lo que debería traducirse en el nacimiento de obligaciones positivas para los Estados dirigidas a garantizar la realización de su contenido: la libre expresión del pueblo en las elecciones del cuerpo legislativo. Algo que, en nuestra opinión, implicaría la adopción de medidas positivas destinadas a asegurar la participación de los ciudadanos en los procesos electorales, así como la correspondencia entre la voluntad popular y el resultado de la elección. Sin embargo, veremos como el reconocimiento de un amplio margen de apreciación nacional lleva al Tribunal de Estrasburgo a reconocer únicamente obligaciones positivas en lo que se refiere a la dimensión institucional del derecho de voto, es decir, a la intervención de los poderes públicos estatales para la celebración de las elecciones, pero no exige una

2 Artículo 3 del Protocolo I: «Las Altas Partes Contratantes se comprometen a organizar, a intervalos razonables, elecciones libres con escrutinio secreto, en condiciones que garanticen la libre expresión de la opinión del pueblo en la elección del cuerpo legislativo».

«Reafirmando su profunda adhesión a estas libertades fundamentales que constituyen las bases mismas de la justicia y de la paz en el mundo, y cuyo mantenimiento reposa esencialmente, de una parte, en un régimen político verdaderamente democrático, y, de otra, en una concepción y un respeto comunes de los derechos humanos de los cuales dependen». 
determinada configuración del sistema electoral ni de las normas de procedimiento electoral que aseguren esa efectividad del derecho de voto.

\section{EL CARÁCTER INTERESTATAL DEL ARTÍCULO 3 DEL PROTOCOLO I Y LA DEFINICIÓN DE LAS FACULTADES SUBJETIVAS QUE INTEGRAN EL CONTENIDO DEL DERECHO}

Pese a este carácter neurálgico de la democracia para el sistema europeo de protección de derechos, el primer borrador del Convenio Europeo de Derechos Fundamentales que se envió al Comité de Ministros para su aprobación no mencionaba el derecho de sufragio dentro de su ámbito de protección. Se argumentó en ese momento que el Convenio había nacido como un instrumento para la protección de derechos individuales y no para definir las estructuras políticas de los Estados, lo que generó una fuerte oposición de los expertos franceses y británicos y la presentación de un nuevo borrador. Finalmente, se introdujeron algunos derechos políticos en el Convenio (derecho de asociación y reunión, por ejemplo) pero hubo que esperar a la adopción del Protocolo I en 1952 para que en el artículo se reconociese la obligación de los Estados unas elecciones libres ${ }^{4}$.

Sin embargo, inicialmente, la antigua Comisión consideró que en el artículo 3 del Protocolo I existía únicamente una garantía institucional de las elecciones libres, que no garantizaba la existencia de derechos individuales sino únicamente obligaciones a los Estados 5 . Así, en los Asuntos X contra la República Federal de Alemania, X, Y y Z contra Bélgica, A. D. Q. y otros contra Bélgica, $X$ contra la República Federal de Alemania y Asunto X contra Holanda concluyó que «el derecho de voto no se encuentra, en cuanto a tal, consagrado en el artículo 3 del Protocolo $I{ }^{6}$ y, en consecuencia, los Estados podrían excluir de la elección

4 Sobre las dificultades que planteo la inclusión de este derecho en el ámbito de protección del Convenio Europeo de Derechos Humanos y la elaboración del Artículo 3 del Protocolo I puede consultarse GOY, RAYMOND (1986): «La garantie européenne du droit à de libres élections législatives: l'article 3 du premier Protocole additionnel à la Convention de Rome», Revue du Droit Public, núm. 5, págs. 1275-1326 y Golubok, S. (2009): «Right to free elections: Emerging guarantees or two layers of protection?», Netherlands Quarterly of Human Rights, núm. 27, págs. 361-390.

5 El número de recursos presentados e inadmitidos fue muy numeroso, Raymond Goy (1986): op. cit, advierte que hasta 1960 se rechazaron 710 de 713 recursos individuales.

6 Decisión de la Comisión (en adelante DCEDH) de 4 de enero de 1959 (Asunto X contra la República Federal de Alemania), demanda n. ${ }^{\circ}$ 530/59; DCEDH de 3 de mayo de 1961 (Asunto X, Y y Z contra Bélgica), demanda n. ${ }^{\circ}$ 1065/61; DCEDH de 18 de septiembre de 1961 (Asunto A. D. Q. y otros contra Bélgica), demanda n. ${ }^{\circ}$ 1028/61; DCEDH de 6 de octubre de 1967 
a ciertas categorías de ciudadanos, como los condenados a penas privativas de libertad o los no residentes, sin que con eso se impida la libre expresión de la opinión del pueblo en la elección del cuerpo legislativo. Aparecen en estas decisiones temas que luego serán recurrentes en la jurisprudencia del Tribunal al analizar la legitimidad de las causas de incapacidad electoral que trataremos con más extensión al ocuparnos del sufragio universal.

Precisamente, la definición del sufragio como universal, que se reconoce sin apenas justificación en las dos últimas decisiones mencionadas, va a ser el leit motiv del cambio de postura de la Comisión en el Asunto $W, X, Y$ y $Z$ contra Bélgica ${ }^{7}$. Para entender esta evolución es conveniente que nos extendamos un poco más sobre los argumentos de la Comisión en estas decisiones.

El Asunto X contra la República Federal de Alemania supone un pequeño pero importante paso para llegar al reconocimiento de derechos subjetivos de participación política. En él, se analiza por la Comisión la legitimidad de la privación del derecho de sufragio — al Sr. X se le había impedido participar en las elecciones del Land del Sarre y en las federales de 1965- a los condenados a penas privativas de libertad. Y, aunque, como vimos, la Comisión niega que del artículo 3 del Protocolo I se derive un derecho individual a participar en las elecciones, sin embargo, la consideración de que «el compromiso de los Estados de celebrar elecciones libres implica el reconocimiento del sufragio universal» le lleva a arrogarse la función de analizar las demandas individuales sobre privación del sufragio para verificar el cumplimiento de esta obligación estatal. Argumentos que se reiteran en el Asunto X contra Holanda, donde confirmaría la legitimidad de las legislaciones nacionales que establecían como causa de incapacidad electoral la participación durante la guerra en crímenes contra la seguridad del Estado o contra los fundamentos de una sociedad democrática.

Unos pocos meses después revisará de manera expresa su jurisprudencia para llegar a la solución contraria en el Asunto $W, X, Y$ y $Z$ contra Bélgica que versará sobre el establecimiento de una edad mínima para ser candidato al Senado belga. Aunque se refiere a un supuesto de capacidad electoral pasiva, sus conclusiones son extrapolables mutatis mutandi al derecho de sufragio activo. A partir de esta decisión la Comisión realiza una interpretación finalista y sistemática del artículo 3 del Protocolo I, rechazando con ello la interpretación literal y formalista que había defendido hasta el momento. Es decir, considerará que el reconoci-

(X contra la República Federal de Alemania) demanda n. ${ }^{\circ}$ 2728/66 y DCEDH de 19 de diciembre de 1974 (Asunto X. contra Holanda) demanda n. ${ }^{\circ}$ 6573/74.

7 DCEDH de 30 de mayo de 1975 (Asunto W, X, Y y Z contra Bélgica), demandas n. ${ }^{\circ} 6745 / 74$ y $6746 / 74$ 
miento de derechos se encuentra en la propia base del Convenio europeo y, como el Protocolo adicional disfruta de la misma naturaleza que el Convenio (artículo 5 del Protocolo I), sea cual sea la redacción del precepto debe entenderse comprendido en su enunciado un derecho individual.

Una vez aceptada esta dimensión subjetiva y para delimitar cual es su contenido, la Comisión recuerda que ya había establecido la obligación de asegurar el sufragio universal como contenido derivado del compromiso de celebrar elecciones libres, Lo que le lleva a concluir que en el mencionado precepto se garantizan, en principio, dos derechos: el derecho de voto y el derecho a presentarse como candidato en la elección del cuerpo legislativo» ${ }^{8}$.

El Tribunal hace suyos estos argumentos de la Comisión en el Asunto Matbieu-Mobin y Clerfayt contra Bélgica, auténtico leading case en materia de derechos de participación política, desarrollando notablemente las previsiones del artículo 3 del Protocolo I a partir de su carácter neurálgico en un régimen político democrático y de su dimensión prestacional ${ }^{9}$. Es precisamente esta dimensión prestacional del derecho lo que explica, según el Tribunal, la «apariencia interestatal de la redacción del precepto» pues, a diferencia de otras disposiciones normativas del Convenio y el Protocolo, está redactado en términos de obligación del los Estados. Con ello hace explícitos los argumentos que sólo pueden intuirse en las decisiones de la Comisión, señalando que no se pretende excluir la presencia de un autentico derecho subjetivo, sino dar más solemnidad al com-

8 DCEDH de 30 de mayo de 1975, Asunto W, X, Y y Z contra Bélgica, demandas n. ${ }^{\circ} 6745 / 74$ y 6746/74. Jurisprudencia que se reiterará a partir de entonces, entre otras muchas, en las DDCEDH de 3 de octubre de 1975 (Asunto X contra el Reino Unido), demanda n. ${ }^{\circ}$ 7096/75; de 18 de mayo de 1976 (Asunto Asociación X, Y y Z contra la república Federal de Alemania), demanda n. ${ }^{\circ}$ 6850/74; de 11 de septiembre de 1976 (Asunto X contra el Reino Unido), demanda n. ${ }^{\circ}$ 7566/76; de 3 de diciembre de 1979 (Asunto X contra Bélgica), demanda n. ${ }^{\circ}$ 8701/79; de 12 de julio de 1983 (Asunto Serge Moreaux y otros contra Bélgica) y de 5 de julio de 1985 (Asunto Stanley Booth-Clibborn y otros contra reino Unido), demanda $11391 / 85$.

9 STEDH de 2 de marzo de 1987 (Asunto Mathieu-Mohin y Clerfayt contra Bélgica). En este caso, los demandantes eran parlamentarios nacionales — senadora y diputado, respectivamente-y, como tales, pretendían formar parte del Consejo flamenco, al que pertenece el distrito administrativo de Hal-Vilvorde por el que se presentaron ambos. Sin embargo, como eran miembros de la comunidad lingüística francesa, habían jurado su cargo parlamentario en francés, lo cual, impedía el acceso al Consejo flamenco. Órgano cuyas atribuciones y competencias, considera el Tribunal Europeo de Derechos Humanos que debe equipararse a las de la Cámara de Representantes y Senado e integrase dentro de la expresión «Cuerpo legislativo» belga al que se refiere el artículo 3. Aunque se trata de un supuesto de sufragio pasivo, el Tribunal Europeo de Derechos Humanos establece una doctrina aplicable a ambas vertientes del derecho de sufragio. 
promiso contraído, reconociéndose así que la obligación primordial de los Estados respecto a este derecho no supone una abstención o no injerencia, como sucede con la mayoría de los derechos civiles y políticos, sino la adopción por el Estado de medidas positivas para «organizar» elecciones democráticas ${ }^{10}$. De ahí concluye, que en este artículo se reconocen varios derechos individuales de participación ${ }^{11}$ : el derecho de voto y el derecho a presentarse como candidato en las elecciones al cuerpo legislativo ${ }^{12}$ — que ya reconociera la Comisión- así como el derecho a, una vez elegido, ejercer como miembro del Parlamento ${ }^{13}$.

Por otro lado, el Tribunal, aplicando su doctrina que niega el carácter absoluto de los derechos ${ }^{14}$, considera la posibilidad de someter a los derechos de participación política a mayores restricciones que a otros derechos (especialmente que a los reconocidos en los artículos 8-11 del Convenio donde se establecen de manera taxativa las razones que pueden justificar la limitación esos derechos), al tratarse de uno de los derechos del Convenio en los que existe un amplio margen de apreciación por parte de los Estados; lo que se traduce en la posibilidad de establecer ciertos requisitos para adaptar sus condiciones de ejercicio a los peculiares factores políticos y sociales de cada Estado que derivan la necesidad de cohonestar fines muy distintos e incluso contradictorios en la legislación electoral: facilitar la representación popular, favorecer la gobernabilidad creando ejecutivos fuertes, conseguir una adecuada representación de todas las zonas del

10 Sobre la noción de obligaciones positivas puede consultarse MOWBRAY, A. (2004): The development of positive obligations under the European Convention on Human Rights by the European Court of Human Rights, Oxford, Portland y AKANDJI-KOMBE, J. F.: Positive obligations under the European Convention on Human Rights (2007), Estrasburgo, Consejo de Europa, para el derecho de voto especialmente págs. 48-50.

11 Una visión conjunta de todos los derechos reconocidos por el artículo 3 del Protocolo I puede encontrarse en GARCÍA ROCA, F. J. (2005): «Del compromiso internacional de los Estados de organizar elecciones libres al derecho de sufragio de los ciudadanos (art. 3 P1)», SANTOLAYA MACHETTI, P. y GARCÍA ROCA, F.J. (Coords.): La Europa de los Derechos: el Convenio Europeo de Derechos Humanos, Madrid, CEPC, págs. 825-854.

12 Véase, por todas, STEDH de 2 de marzo de 1987 (Asunto Mathieu-Mohin y Clerfayt contra Bélgica), $\S \S 50$ y 51 .

13 Véanse, por todas, las SSTEDH de 11 de junio de 2002 (Asunto Selim Sadak y otros contra Turquía), § 33; de 15 de septiembre de 2006 (Asunto Lykourezos contra Grecia), § 50; de 5 de abril de 2007 (Asunto Ilicak contra Turquía), § 30; de 5 de abril de 2007 (Asunto Kavakçi contra Turquía), § 41, de 7 de febrero de 2008 (Asunto Kovach contra Ucrania), § 48 y de 10 de abril de 2008 (Asunto Paschalidis, Koutmeridis y Zaharakis contra Grecia), § 25.

14 STEDH de 2 de marzo de 1987 (Asunto Mathieu-Mohin y Clerfayt contra Bélgica), § 52 y, entre otras, SSTEDH de 1 julio 1997 (Asunto Gitonas y otros contra Grecia, § 39; de 18 de febrero de 1999 (Asunto Matthews contra el Reino Unido), § 63; de 9 de abril de 2002 (Asunto Podkolzina contra Letonia), § 33 y de 11 de enero de 2005 (Asunto Py contra Francia), § 47. 
territorio, etc. ${ }^{15}$. Sin embargo, estas limitaciones o restricciones no pueden ser arbitrarias ni afectar en ningún caso un contenido mínimo del derecho ${ }^{16}$. Contenido mínimo que se identifica con el respeto de la libre expresión del pueblo en las elecciones del cuerpo legislativo lo que, a juicio del Tribunal, supone que las condiciones o limitaciones impuestas al derecho «deben reflejar (o, al menos, no oponerse a) la preocupación de mantener la integridad y la efectividad de un proceso electoral que trate de determinar la voluntad del pueblo a través del sufragio universal» ${ }^{17}$. A partir de esta máxima, el Tribunal Europeo de Derechos Humanos ha ido identificando una serie de condiciones subjetivas o facultades que aseguran ese respeto a la libre expresión popular como son la universidad del sufragio, la libertad de voto y la igualdad de trato de los electores de las que nos ocuparemos con mayor extensión en los próximos epígrafes (III, IV y V). Además, el artículo completa esta exigencia de «elecciones libres» con dos requisitos de carácter objetivo: la periodicidad de las elecciones y el ámbito de la decisión popular, con las que concluiremos este análisis de la jurisprudencia del Tribunal Europeo de Derechos Humanos sobre el derecho de voto (VI).

\section{EL SUFRAGIO UNIVERSAL}

Hemos visto como para los órganos del Convenio la exigencia de sufragio universal que se consideraba implícita a la obligación de convocar elecciones libres, ha sido determinante para el nacimiento de un derecho fundamental de participación política a partir del artículo 3 del Protocolo I. Para el Tribunal el sufragio universal implica que el voto no puede considerarse un privilegio ${ }^{18}$ de manera que el principio democrático en pleno siglo XXI exige que «la presunción juegue a favor de la concesión de este derecho al número más grande de personas ${ }^{19}$.

15 Sobre el significado del «margen de apreciación» estatal vid. VASEL, J. J. (2009): «El "margin of appreciation" como elemento clave en el Derecho Constitucional Europeo», Revista de Derecho Constitucional Europeo, núm. 11, págs. 189-208.

16 Por todas, STEDH de 18 de febrero de 1999 (Asunto Matthews contra el Reino Unido), $§ 63$.

17 SSTEDH de 6 de octubre de 2005 (Gran Sala, Asunto Hirst contra Reino Unido), § 62, de 5 de abril de 2007 (Asunto Kavakçi contra Turquía), § 41 y 5 de abril de 2007 (Asunto Ilicak contra Turquía), $\S 30$.

18 Sobre la evolución de esta concepción del electorado-función —es decir, del voto como una atribución de determinadas personas que por pagar un censo e ejercer determinadas profesiones se consideraban que tenían interés en la cosa pública y tenían capacidad para conocer el interés de la Nación - a la del electorado-derecho y, en consecuencia, perteneciente a todos los miembros de la comunidad política vid. PRESNO LINERA, M. A. (2003): El derecho de voto, Madrid, Tecnos, págs. 49-101.

19 SSTEDH de 30 de marzo de 2004 (Asunto Hirst núm. 2 contra Reino Unido), § 59 y de 15 de marzo de 2012 (Asunto Sitaropoulos y Giakoumopoulus contra Grecia), § 67. 
No obstante, la necesidad de cohonestar fines muy distintos, e incluso contradictorios en la legislación electoral, determina la presencia de un amplio margen de apreciación de los Estados en la configuración legal de los requisitos para ejercer el derecho de sufragio. Por eso, el Tribunal ha reconocido que las leyes pueden ponderar diversos fines y establecer una pluralidad de requisitos atendiendo a las circunstancias políticas, sociales e históricas del país ${ }^{20}$. Así, en la fijación de los requisitos de capacidad electoral la mayoría de las legislaciones nacionales tienen en cuenta la nacionalidad, la residencia o una duración mínima de ésta, la inscripción en el censo, la condena penal, la discapacidad, etc. Y el papel del Tribunal a la hora de controlar su adecuación a la exigencia de sufragio universal se limita a constatar que no se lesione la esencia del derecho o su efectividad y que las restricciones no sean arbitrarias.

En el primer supuesto nos encontramos en el Asunto del Partido Laborista de Georgia contra Georgia, donde tras mostrarse bastante tolerante con las irregularidades que se produjeron en las primeras elecciones democráticas tras la dimisión de Shervernaze, especialmente en la composición de las Juntas electorales cuyo carácter independiente era más que improbable pese a no haberse podido demostrar ningún fraude electoral, de manera que «lo que podría considerarse en un contexto como algo inaceptable puede permitirse en otro». Sin embargo, considera que se ha vulnerado la efectividad del derecho al sufragio por las numerosas irregularidades en la inscripción de los votantes que impidieron a millares de georgianos expresar su opinión en las primeras elecciones. También apreció que se había impedido la efectividad del derecho en el Asunto Aziz contra Chipre $^{21}$, donde estimó contraria al Convenio la exclusión de la minoría nacional turco-chipriota que, por diversos problemas en la confección de las listas del censo, tenía suspendidos sus derechos electorales desde 1963 y en el

20 Sobre la influencia de este tipo de condicionamientos en la jurisprudencia del Tribunal Europeo de Derechos humanos vid. BURATTI, A. (2012): «El uso de la historia en la jurisprudencia del Tribunal Europeo de Derechos Humanos», Revista de Derecho Constitucional Europeo, núm. 18, (se ha consultado la versión electrónica disponible en http://www.ugr.es/ redce/REDCE18/articulos/13_BURATTI.htm).

21 STEDH de 22 de junio de 2004 (Asunto Aziz contra Chipre). En esta sentencia el Tribunal Europeo de Derechos Humanos resuelve la demanda interpuesta por un ciudadano chipriota, Ibrahim Aziz, a quien el Gobierno de esta isla mediterránea había suspendido los derechos de participación política impidiéndole inscribirse en el censo electoral. La Constitución chipriota consagra la existencia de dos listas del censo: una para la comunidad griega y otra para la comunidad turca. Sin embrago, a raíz de la ocupación turca de la isla en el año 1963, los representantes de la comunidad turca se retiraron de los órganos constitucionales del Estado y los miembros de la minoría turco-chipriota residentes en el área controlada por el Gobierno, al no poderse integrar en el censo de la comunidad griega, quedaron impedidos de participar en la vida política del país. 
Asunto Mathews contra el Reino Unido $0^{22}$ en el que declaró injustificada la privación del derecho de voto en las elecciones al Parlamento Europeo de los residentes en Gibraltar.

Por otro lado, el Tribunal ha convalidado una serie de requisitos de capacidad electoral como son la nacionalidad, la residencia y la edad. En efecto, son muchas las decisiones de la Comisión y del Tribunal en las que se estima que «la nacionalidad, la residencia y la edad forman parte de criterios comúnmente aceptados por los Estados a la hora de determinar la condición de elector ${ }^{23}$. Esto le lleva a realizar un control más débil sobre este tipo de criterios limitándose a comprobar la falta de arbitrariedad mediante la constatación de un fin legítimo que justifique la privación del derecho de voto.

Sólo he encontrado un caso en el que se ponga al los órganos del Convenio europeo en la tesitura de responder a un extranjero sobre la privación del derecho de sufragio en el Estado de residencia, el Asunto Luksch contra Italia ${ }^{24}$, en el que un ciudadano alemán se queja de su exclusión del voto para las elecciones a Consejos municipales y provinciales en Italia.

En relación con el criterio de la residencia del elector, ya desde la antigua Comisión, se han admitido una pluralidad de razones que pueden justificar las exclusión de los nacionales ausentes: la presunción de que los ciudadanos no residentes no se encuentran directamente o, cuando menos, continuamente afectados por los problemas de su país y no los conocen tan bien (1); el hecho de que los ciudadanos que residen en el extranjero no tienen apenas influencia en la selección de los candidatos y en la elaboración de los programas electorales (2); resulta en algunos casos impracticable y a veces no deseable que los candidatos presenten las diferentes cuestiones electorales a los ciudadanos que viven en el extranjero para garantizar la libre expresión de su opinión (3) la necesaria correlación que debe existir entre el derecho al voto en las elecciones al Parlamento y el estar directamente afectado por las acciones de los órganos políticos electivos (4) y, finalmente las dificultades que entraña evitar el fraude electoral en el voto por correo (5) son elementos que debe tener en cuenta el legislador nacional a la hora de ponderar el principio de sufragio universal con el imperativo de certeza

22 STEDH de 18 de febrero de 1999 (Asunto Matthews contra el Reino Unido). En esta sentencia el Tribunal Europeo de Derechos Humanos resuelve la demanda de una ciudadana gibraltareña que denuncia que el Reino Unido ha incumplido el artículo 3 del Protocolo I al no organizar en Gibraltar elecciones libres al Parlamento Europeo.

23 Por todas, véase las DDCEDH de 11 de diciembre de 1976 (Asunto X contra Reino Unido), demanda n. ${ }^{\circ}$ 7566/76 y de 21 de mayo de 1997 (Asunto Luksch contra Italia), demanda n. ${ }^{\circ} 27614 / 95$.

24 DCEDH de 21 de mayo de 1997 (Asunto Luksch contra Italia), demanda n. ${ }^{\circ}$ 27614/95. 
del voto y otras consideraciones de carácter práctico ${ }^{25}$. En el Asunto Py contra Francia, convalidó la exigencia de diez años de residencia para poder participar en las elecciones al Congreso de Nueva Caledonia al justificarse por razones históricas y políticas en la necesidad de asegurar un vínculo identitario de la comunidad política ${ }^{26}$.

Respecto a la edad, sólo he encontrado un caso, que además no entraría directamente dentro del objeto de este trabajo al referirse al sufragio pasivo. Sería el ya tratado Asunto $W, X$ y $Y$ contra $Z^{27}$ (donde la Comisión reconoció la existencia de derechos subjetivos de participación política por primera vez) en el que estimó que no se podía considerar arbitraria ni exorbitante exigir una edad de 25 años para formar parte de la Cámara de Representantes ni tampoco 40 años para ser senador, pues en un sistema bicameral suele ser habitual la exigencia de una mayor experiencia política para los miembros de una de las Cámaras.

En el Asunto Albanese contra Italia se apreció también la vulneración del artículo 3 del Protocolo 1, por la aplicación de una medida prevista en el artículo 2 del Decreto del Presidente de la República n. 223, de 20 de marzo de 1967 que excluía a los condenados en procesos civiles de quiebra de sus derechos de participación política al considerarse que se trataba de una medida aflictiva e infamante que no obedecía a ningún fin legítimo ${ }^{28}$.

25 Véanse las DDCEDH de 11 de diciembre de 1976 (Asunto X contra Reino Unido), demanda n. ${ }^{\circ} 7566 / 76$; de 28 de febrero de 1979 (Asunto X contra Reino Unido), demanda n. ${ }^{\circ} 7730 / 76$; de 6 de octubre de 1981 (X y asociación Y contra Italia), demanda n. ${ }^{\circ}$ 8987/80; 13 de mayo de 1982 (Asunto X contra Reino Unido), demanda n. ${ }^{\circ}$ 8873/80.

26 STEDH de 11 de enero de 2005 (Asunto Py contra Francia). En esta Sentencia, el Tribunal Europeo de Derechos Humanos resuelve la demanda del Sr. Bruno Py, un ciudadano francés que trasladó su residencia Nueva Caledonia para desempeñar un cargo funcionarial en esta colectividad territorial francesa y se empadronó en la capital, Nouméa en el año 1995. En 1998 solicitó formar parte del censo electoral para el referéndum de autodeterminación y en 1999 pidió de nuevo su inscripción en el censo electoral para participar en las elecciones al Congreso de Nueva Caledonia y de las Asambleas provinciales. Ambas peticiones fueron rechazadas. En la decisión del Tribunal Europeo de Derechos Humanos adquiere especial relevancia en orden a justificar la necesidad de la medida, la existencia de necesidades locales específicas, como es la propia situación histórica de Nueva Caledonia muy agitada resultado de un conflicto sangriento y en la que la limitación del derecho de voto se ha considerado un elemento esencial para el apaciguamiento. Vid. especialmente, $\S 62$.

27 DCEDH de 30 de mayo de 1975, Asunto W, X, Y y Z contra Bélgica, demandas n. ${ }^{\circ} 6745 / 74$ y $6746 / 74$.

28 STEDH de 23 de marzo de 2006 (Asunto Albanese contra Italia), § 49; de 23 de marzo de 2006 (Asunto Vitello contra Italia), $\S \$ 2$ y 43; Reiterada en las SSTEDH de 23 de marzo de 2006 (Asunto Campagnano contra Italia), $\$ 48$ y 49; de 24 de mayo de 2006 (Asunto Bova contra Italia), §§ 24 y 25; de 24 de mayo de 2006 (Asunto Pastuso contra Italia), §§ 33 y 34; de 29 de junio de 2006 (Asunto Chiumiento contra Italia), §§ 31 y 32; de 29 de junio de 2006 
Mención aparte merecen el análisis de la exclusión del sufragio a los condenados porque en él podemos comprobar una evolución desde los primeros casos resueltos por la Comisión de manera que, en lugar de un control débil en el que sólo se exige la existencia de un fin legítimo que justifique esta restricción del derecho, a partir del asunto Hirst contra Reino Unido ${ }^{29}$ realiza un control estricto, rechazando la doctrina del amplio margen de apreciación nacional fundada en la existencia de una tradición histórica incuestionable, lo que le lleva a tener que justificar su decisión según el esquema del juicio de proporcionalidad.

Así, mientras la antigua Comisión consideró legítimos la privación del derecho de sufragio por la comisión de delitos de traición al Estado o contra los principios de la sociedad democrática durante la guerra ${ }^{30}$. E incluso, en el caso del objetor holandés - Asunto H. contra Holanda, en el que se cuestionaba la regla en virtud de la cual la condena a una pena privativa de libertad de más de un año llevaba aparejada la privación del derecho de voto durante tres años- recurrió al amplio margen de apreciación nacional para considerar justificada la privación de derecho a los condenados ${ }^{31}$.

Sin embargo, en el Asunto Hirst contra Reino Unido el Tribunal cambia su modo de proceder en este tipo de demandas, aplicando un test más estricto que exige controlar no sólo la arbitrariedad sino además la proporcionalidad de la medida. Así, respecto a la legitimidad del fin, concluyó que en la legislación británica no existía una relación lógica entre la privación del derecho de voto y la imposición de una pena privativa de libertad. El Gobierno demandado había argumentado que con esta medida se pretendía la prevención y castigo de los delitos y la intensificación de la responsabilidad civil y el respeto a las normas del Estado de Derecho. Pero el Tribunal no acepta que esos fines sean adecuados, poniendo en duda que la privación del voto tenga alguna eficacia disuasoria de

(Asunto La Frazia contra Italia), §§ 35 y 36; de 29 de junio de 2006 (Asunto Vertucci contra Italia); de 13 de julio de 2006 (Asunto Vincenzo Taiani contra Italia), $\S 34$ y 35 y de 20 de julio de 2006 (Asunto Taiani contra Italia), $\S \$ 40$ y 41.

29 SSTEDH de 30 de marzo de 2004 (Asunto Hirst núm. 2 contra Reino Unido) y de 6 de octubre de 2005 (Gran Sala, Asunto Hirst contra Reino Unido). Resuelve en estas Sentencias el Tribunal Europeo de Derechos Humanos la demanda interpuesta por un recluso británico que había sido condenado a cadena perpetua discrecional por haber cometido un homicidio involuntario. En aplicación de la Representation of the People Act vigente entonces, cualquier condena a pena privativa de libertad conllevaba automáticamente la privación del derecho de voto.

30 DCEDH de 19 de diciembre de 1974 (Asunto X contra Holanda), demanda n. ${ }^{\circ}$ 6573/74 y de 3 de diciembre de 1979 (Asunto X contra Bélgica), demanda n. ${ }^{\circ}$ 8701/79.

31 DCEDH de 4 de julio de 1983 (Asunto H. contra Holanda), demanda n. ${ }^{\circ}$ 9914/82. 
los delitos. Además estima que la medida es desproporcionada porque se impone por la legislación con carácter general y de manera automática. A juicio del Tribunal la exclusión del derecho de sufragio debería configurarse como una excepción en las legislaciones nacionales y ser adoptada por un juez, acompañada de una argumentación específica en las que se valoren las circunstancias de cada caso, atendiendo principalmente a la naturaleza y gravedad de la infracción cometida, su relación con la incapacidad electoral y la situación personal del condenado ${ }^{32}$.

También ha exigido un test estricto en relación a la privación del voto a personas con problemas de salud mental o discapacidad intelectual en el Asunto Alajos Kiss contra Hungria ${ }^{33}$. Para entender las conclusiones alcanzadas, debe tenerse en cuenta que en la legislación de este país, la sujeción a cualquier régimen de protección de la incapacidad, con independencia de las causas que la motivaron y del alcance de la misma, llevaba aparejada la exclusión de los derechos políticos. En este caso, aplicando la doctrina establecida en el caso Hirst, el Tribunal declaró incompatible con el artículo 3 del Protocolo 1 la privación automática del derecho de voto a todas las personas que padecen algún tipo de desorden mental o intelectual, exigiendo que esta medida sólo pueda ser adoptada tras una evaluación judicial individualizada de sus capacidades y necesidades, en definitiva, de su aptitud para el ejercicio del voto.

Parece extraerse de esta forma de actuar del Tribunal la necesidad de un plus de argumentación cuando la privación del sufragio puede afectar a personas con riesgo de exclusión social, como presos o disminuidos psíquicos o intelectuales, por tratarse de colectivos que han sido discriminados en el pasado.

\section{EL VOTO LIBRE}

La definición del sufragio como libre es consustancial a la noción de autodeterminación política de los ciudadanos que subyace al principio democrático.

32 SSTEDH de 4 de octubre de 2010 (Asunto Frold contra Austria), $§ 35$ y de 25 de mayo de 2012 (Asunto Scoppola contra Italia), § 102. Son los casos de dos ciudadanos condenados a cadena perpetua por asesinato. Ambos recurren ante el Tribunal Europeo de Derechos Humanos su exclusión de las listas electorales por estar sometido a una pena de prisión de duración superior a un año o cinco años, respectivamente.

33 SSTEDH de de marzo de 2004 (Asunto Alajos Kiss contra Hungría). El demandante, que había sido incapacitado parcialmente como consecuencia de un desorden de la conducta que le incitaba a comprar de manera compulsiva, se queja de que en Hungría cualquier declaración de incapacidad, con independencia de su gravedad y del alcance de ésta, lleva aparejada la privación de los derechos de participación política. 
Para que pueda hablarse de democracia es imprescindible que los votos expresados —o incluso los no expresados - sean fruto de la decisión libre y consciente de los ciudadanos ${ }^{34}$. Por eso, la libertad en el proceso de formación de la decisión de los ciudadanos es uno de los principios esenciales del Derecho electoral que ha sido acogido no sólo en los textos constitucionales sino también en diversos documentos internacionales, entre ellos, el artículo 3 del Protocolo I. Este precepto incide en dos ocasiones sobre la necesidad de asegurar unas elecciones «libres» y establece uno de los mecanismos para alcanzar ese fin: la votación secreta. Además, el Tribunal Europeo de Derechos Humanos subraya que el sufragio libre es la piedra angular de la protección concedida por el Convenio ${ }^{35}$. No en vano hemos dicho que el contenido mínimo del derecho asegurado por el artículo 3 viene expresado por el respeto de la libre expresión del pueblo en las elecciones del cuerpo legislativo.

En palabras del Tribunal, la libertad de voto significa que las elecciones no se pueden celebrar bajo ninguna forma de presión en la elección de los candidatos y que, en su elección, el votante no puede verse inducido a votar por in partido u otro ${ }^{36}$. En su jurisprudencia, el principio del voto libre se configura no sólo en su sentido tradicional como ausencia de coacción física al elector (dimensión subjetiva), sino también como el mantenimiento de unas condiciones objetivas de libertad que permitan la libre formación de la opinión individual del votante (dimensión objetiva) ${ }^{37}$. No obstante, es posible apreciar una evolución entre las primeras decisiones de la Comisión y la posición del Tribunal.

En los primeros casos que se plantearon a la Comisión, se identificaba el contenido del precepto únicamente con la dimensión subjetiva de la libertad de voto, definida como la libertad de los votantes de expresar sus deseos; lo cual implica el respeto de las condiciones que protejan a los electores de toda forma de coacción o amenaza ya sea de las autoridades ya de los particulares, asegurándose con

34 En este sentido, vid. BÖCKENFÖRDE, E. W. (2000): «La democracia como principio constitucional», ÍDEM: Estudios sobre el Estado de Derecho y la democracia, Madrid, CEPC, pág. 47 y GARCÍA PELAYO, M. (1986): El Estado de partidos, Madrid, Alianza, pág. 69.

35 STEDH de 11 de enero de 2007 (Asunto Partido Conservador Ruso de Empresarios contra Rusia, § 71.

36 SSTEDH de 11 de enero de 2007 (Asunto Partido Conservador Ruso de Empresarios contra Rusia, § 71 y de 8 de julio de 2008 (Gran Sala, Asunto Yumak y Sadak contra Turquía), § 108.

37 Sobre estas dimensiones de la libertad de voto en nuestra doctrina resulta imprescindible la consulta de SÁNCHEZ MUÑOZ, O. (2007): La igualdad de oportunidades en las competiciones electorales, Madrid, CEPC y FERNÁNDEZ VIVAS, Y. (2007): Igualdad y partidos políticos. Análisis constitucional y comparado de la igualdad de oportunidades de los partidos politicos, Madrid, Congreso de los Diputados. 
ello que en el procedimiento de emisión de voto puedan dar su voto a los candidatos o listas de su preferencia ${ }^{38}$.

Esta definición le permitió a la Comisión confirmar la convencionalidad del voto obligatorio afirmando, en el Asunto X contra Austria ${ }^{39}$, que la obligación de presentarse a las urnas, no determina que el voto no sea libre porque, en este caso, el elector no tenía que elegir obligatoriamente a uno de los candidatos incluidos en la papeleta de votación, sino que podía optar por votar en blanco o emitir un voto nulo incluso. Por tanto, es la ausencia de presión sobre el elector para escoger a los candidatos lo que permitiría seguir calificando a esas elecciones como libres. Argumentación que reprodujo cuando tuvo que pronunciarse sobre el sufragio libre en varias demandas en las que se cuestionaba la compatibilidad con libertad de la opción del legislador nacional a favor de un sistema electoral mayoritario en lugar de uno proporcional o la regulación de los espacios electorales ${ }^{40}$. Nos resulta interesante traer a colación esta última cuestión porque en el Asunto Tete contra Francia $I I^{41}$, rechazó controlar las dudas sobre regulación del reparto de los espacios electorales en la radio y televisión públicas por considerar que entraban dentro del amplio margen de apreciación de los Estados, a pesar de los peligros que puede entrañar el papel de las autoridades y de los medios de comunicación pública para la libre formación de la opinión de los ciudadanos.

El Tribunal ha extendido el contenido de esta garantía, entendiendo que la libertad de voto impone además dos importantes obligaciones a los Estados para garantizar el mantenimiento de unas condiciones objetivas de libertad que permitan la libre formación de la opinión individual del votante (dimensión objetiva): una primera de neutralidad estatal y de igualdad de trato de la candidaturas, especialmente en lo que atañe al uso de los medios de comunicación y de los espacios públicos para la disposición de sus carteles o la celebración de sus mítines, el reparto de los fondos públicos entre las candidaturas, la libertades de expresión, reunión y manifestación de las mismas durante la campaña electoral, etc. Y, en segundo lugar, una obligación positiva de las autoridades públicas que deben

38 STEDH de 11 de enero de 2007 (Asunto Partido Conservador Ruso de Empresarios contra Rusia, $\S 73$.

39 DCEDH de 22 de marzo de 1972 (Asunto X. contra Austria), demanda n. ${ }^{\circ}$ 4982/71.

40 DDCEDH de 6 de octubre de 1976 (Asunto X. contra Reino Unido), demanda n. ${ }^{\circ} 7140 / 75$, de 8 de marzo de 1978 (Asunto Kennedy Lindsay y otros contra Reino Unido), demanda n. ${ }^{\circ}$ 8364/78; de 12 de julio de 1983 (Asunto Serge Moureax y otros contra Bélgica), demandas n. ${ }^{\circ}$ 6745/74 y 6746/74; de 8 de diciembre de 1981 (Asunto X contra Islandia), demanda n. ${ }^{\circ}$ 8941/80 y de 9 de diciembre de 1987 (Asunto Tete contra Francia), demanda 11123/84.

41 DCEDH de 10 de marzo de 1988 (Asunto Tete contra Francia II), demanda 11802/85. 
presentar al electorado las candidaturas recibidas e informarle correctamente y de manera neutral sobre los candidatos ${ }^{42}$.

De esta enumeración puede colegirse como muchas veces en la dimensión objetiva de la libertad de voto se unen la vertiente activa y pasiva del derecho de sufragio. Por eso el Tribunal advierte que un aspecto que debe tener en cuenta a la hora de analizar las restricciones del derecho a ser elegido es el de las repercusiones que puedan tener en el derecho de los ciudadanos a votar de acuerdo con su percepción de cuál es el candidato que mejor defenderá sus intereses ${ }^{43}$. Al mismo tiempo, es también consciente de las dificultades que entraña apreciar la lesión individualizada del derecho subjetivo de un votante concreto fundada en la vulneración de las condiciones objetivas de la elección que permiten la formación libre de la voluntad del cuerpo electoral y cuando raramente así lo ha considerado, no ha estimado directamente una lesión del derecho de los votantes, sino más bien una vulneración indirecta corolario de la violación del derecho del representante que indebidamente ha sido excluido de la contienda electoral o al que se le ha impedido el ejercicio de su mandato parlamentario ${ }^{44}$.

La mayoría de los supuestos en los que el Tribunal ha aludido a esta faceta de la libertad de voto ha sido en asuntos en los que impugnaban la adecuación al Convenio de algún motivo de exclusión de los candidatos de la competición

42 STEDH de 11 de enero de 2007 (Asunto Partido Conservador Ruso de Empresarios contra Rusia, § 72 .

43 SSTEDH de 27 de abril de 2010 (Grán Sala) y de 18 de noviembre de 2008 (Asunto Tanase y Chirtoaca contra Moldavia). En estos pronunciamientos, el Tribunal Europeo de Derechos Humanos resuelve las demandas de un ciudadano moldavo, el sr. Chirtoaca, y otro rumano con doble nacionalidad, el sr. Tanase, que pretenden presentarse como candidatos en las próximas elecciones moldavas pero que, sin embargo, se consideran afectados por la reforma de la ley electoral moldava que ha aumentado la barrera electoral de un $4 \%$ a un $6 \%$, establece la prohibición de coaliciones electorales e impide el acceso al Parlamento a ciudadanos con nacionalidad múltiple.

44 STEDH de 11 de enero de 2007 (Asunto Partido Conservador Ruso de Empresarios contra Rusia), § 76. En esta Sentencia, el Tribunal Europeo de Derechos Humanos resuelve la demanda interpuesta contra Rusia por el Partido Conservador Ruso de Emprendedores y dos ciudadanos que se presentaron a las elecciones de 1999 en la lista de este mismo partido, motivada por el hecho de que la Comisión Electoral Central había negado la proclamación de la candidatura del Partido. La falta de proclamación obedeció a que el segundo de los candidatos de la lista electoral había sido excluido de la candidatura por la propia Comisión Electoral, al haber proporcionado informaciones falsas sobre su actividad profesional y patrimonio en aplicación de lo dispuesto por el artículo 51.11 de la Ley Electoral que preveía que la retirada de los tres primeros candidatos de la lista del partido conllevaba la no proclamación o el rechazo de la ya producida. Debe tenerse en cuenta que el 25 de abril de 2000 el Tribunal Constitucional de la Federación Rusa declaró la inconstitucionalidad del mencionado precepto de la Ley Electoral. 
electoral. Así ocurre en los asuntos Gitonas y otros contra Grecia ${ }^{45}$, Melnychenko contra Ucrania ${ }^{46}$, Zdanoka contra Lituania ${ }^{47}$, Partido Conservador Ruso de los Empresarios contra Rusia ${ }^{48}$, Krasnov y Skouratov contra Rusia ${ }^{49}$ y Sarukbanyan contra Arme$n i a^{50}$. En todos ellos, los demandantes alegaban que su exclusión de las listas electorales o la anulación de su elección habían sido ilegítimas. El Tribunal responde con su habitual doctrina del amplio margen de apreciación por parte de los Estados a la hora de establecer los requisitos para acceder a los cargos parlamentarios pero que, en todo caso, deben obedecer a finalidades que no se arbitrarias ni irrazonables y que, en estos casos, se reducen a un origen común: la de garantizar la independencia de representante o, lo que a nosotros nos interesa en este punto, la de asegurar la libre elección de los ciudadanos. Si leemos los antecedentes de la mayoría de los asuntos citados, la exclusión de las candidatu-

45 STEDH de 1 de julio de 1997 (Asunto Gitonas y otros contra Grecia), §§ 39 y 40. En esta Sentencia el Tribunal Europeo de Derechos Humanos resuelve la demanda interpuesta por cinco ciudadanos griegos que desempeñaban su actividad profesional en determinados organismos públicos griegos cuya elección al Parlamento había sido anulada por el Tribunal Supremo al considerar que sus cargos públicos estaban incluidos entre las causas de inelegibilidad enunciadas en el artículo 56.3 de la Constitución.

46 STEDH de 19 de octubre de 2004 (Asunto Melnychenko contra Ucrania), § 55. En esta Sentencia, el Tribunal Europeo de Derechos Humanos resuelve la demanda de. un ciudadano ucraniano que había sido excluido de las listas del Partido Socialista ucraniano que había proporcionado información falsa sobre su residencia.

47 STEDH de 16 de marzo de 2006 (Asunto Zdanoka contra Letonia), § 106. En esta Sentencia, el Tribunal Europeo de Derechos Humanos resuelve la demanda interpuesta contra Letonia por un ciudadano que había sido excluido de las listas electorales de la coalición electoral «Partido por los derechos humanos en una Letonia unida» en las elecciones del Parlamento Europeo de 2002 por pertenecer al partido Comunista.

48 STEDH de 11 de enero de 2007 (Asunto Partido Conservador Ruso de Empresarios contra Rusia), $\$ 49$.

49 STEDH de 19 de julio de 2007 (Asunto Krasnov y Skouratov contra Rusia), § 44. En esta Sentencia, el Tribunal Europeo de Derechos Humanos resuelve las demandas de dos ciudadanos rusos que han visto rechazada su candidatura electoral porque habían proporcionado informaciones falsas sobre su actividad profesional y su pertenencia al Partido Comunista de la Federación Rusa. El Sr. Krasnov había afirmado que era presidente de un consejo de distrito de Moscú cuando ya había dejado de serlo mientras que el sr. Skuratov no había dicho que realizaba tareas docentes en la Universidad sino sólo que era Director del departamento de derecho Constitucional y no había añadido el boletín de afiliación al Partido Comunista aunque sí había dicho que estaba afiliado a este partido.

50 STEDH de 27 de mayo de 2008 (Asunto Sarukhanyan contra Armenia), § 39. En esta Sentencia, el Tribunal Europeo de Derechos Humanos resuelve la demanda de un ciudadano armenio contra Letonia cuya candidatura fue excluida por considerar la Comisión Electoral de Distrito que el demandante había proporcionado una información falsa sobre la propiedad de un inmueble. 
ras obedeció a la aportación de datos falsos sobre la actividad profesional, el patrimonio o la afiliación política de los candidatos. Una exigencia que no puede considerarse arbitraria porque precisamente esta clase de información permite a los electores forjarse una opinión sobre los diferentes candidatos y elegir, así, de una manera informada y libre.

Además, debe tenerse en cuenta que el Tribunal cuando analiza las causas de inelegibilidad realiza un escrutinio más estricto sobre la las medidas limitadoras que afectan al derecho de voto de los electores que cuando sólo está en juego el derecho a presentarse como candidato. Así, cuando se ve involucrado el aspecto activo del sufragio considerará si las condiciones restrictivas vienen impuestas por la ley, no menoscaban el derecho de que se trata hasta el punto de afectar a su esencia y privarle de su efectividad, persiguen un fin legítimo y las medidas empleadas no se revelan desproporcionadas ${ }^{51}$. Por el contrario, cuando sólo considera implicado el sufragio pasivo, aplica el test débil, limitándose a verificar la ausencia de arbitrariedad de los procedimientos internos que conducen a privar a un individuo de su condición de elegible ${ }^{52}$.

En resumidas cuentas, en la jurisprudencia del Tribunal Europeo de Derechos Humanos la faceta objetiva de la libertad de voto se presenta como una finalidad legitima que justifica limitaciones o restricciones en los derechos de los candidatos o una obligación para los Estados en su actuación respecto a las diferentes candidatos que asegure la neutralidad estatal en su comportamiento y el respeto de la igualdad de oportunidades de las candidaturas, garantizándose con ello la libertad en la formación y emisión de voto de los ciudadanos.

\section{LA IGUALDAD DE VOTO}

El Tribunal Europeo de Derecho Humanos considera la igualdad del voto es una exigencia derivada directamente del contenido esencial del derecho. Los pronunciamientos en torno a esta condición de ejercicio del sufragio han tenido su origen casi siempre en impugnaciones relacionadas con alguno de los elementos del sistema electoral. Sin embargo, desde las primeras decisiones de la Comisión, ha aplicado a los sistemas electorales la doctrina del amplio margen de apreciación

51 SSTEDH de 16 de marzo de 2006 (Asunto Zdanoka contra Letonia), § 115 y de 18 de febrero de 1999 (Asunto Matthews contra el Reino Unido), § 63.

52 Véanse, por todas, las STEDH de 24 de junio de 2008. (Asunto Adamsons contra Letonia), $\S 112$ e), de 30 de junio de 2009 (Asunto Etxeberria y otros contra España), $§$ 47-50 y de 7 de diciembre de 2010, (Asunto Eusko Abertzale Ekintza - Acción Nacionalista Vasca EAE-ANV contra España), § 51. 
nacional, al tratarse de una cuestión en la que priman las circunstancias históricas y las tradiciones de los países y responder los sistemas electorales a objetivos muchas veces difíciles de armonizar e, incluso, contrarios. Se trata de un lado, de reflejar con fidelidad las opiniones del pueblo y de otro de canalizar las distintas corrientes ideológicas presentes en la sociedad para promover la formación de una voluntad política dotada de suficiente claridad y coherencia. Así, ciertas restricciones que pueden resultar inadmisibles en un determinado sistema electoral pueden justificarse en otro en atención al objetivo que prime en cada Estado. Ahora bien, ello no resulta incompatible con el respeto del contenido del derecho, de manera que el concreto sistema electoral debe asegurar las condiciones que permitan la libre expresión del pueblo en la elección del Cuerpo Legislativo y la igualdad de trato de los ciudadanos en sufragio activo y pasivo ${ }^{53}$.

Así, por ejemplo, en el Asunto Paschalidis, Koutmeridis y Zaharakis contra Grecia $^{54}$, el Tribunal declaró que el cambio en la interpretación jurisprudencial sobre el recuento de los votos en blanco en la determinación del cociente electoral supuso un trato desigual de los votantes de las circunscripción de Macedonia Central, única a la que afectó la decisión del Tribunal Supremo griego, respecto al resto de ciudadanos griegos y, con ello, una alteración de la voluntad popular $^{55}$.

No obstante, este principio de igualdad de voto es entendido por el Tribunal en un sentido meramente formal, como igualdad en la aplicación de la ley, es decir, igualdad en la existencia de unas mismas condiciones de ejercicio del derecho a todos los electores sin que ello implique otorgar el mismo peso en el valor a los sufragios ni la misma oportunidad de éxito a todos los candidatos ${ }^{56}$. Por ello, tiene sentado la Corte que el artículo 3 del Protocolo I al Convenio Europeo de Derechos Humanos no obliga a establecer un sistema electoral basa-

53 STEDH de 2 de marzo de 1987 (Asunto Mathieu-Mohin y Clerfayt contra Bélgica), § 54.

54 STEDH de 10 de abril de 2008 (Asunto Paschalidis, Koutmeridis contra Grecia). En esta Sentencia, el Tribunal Europeo de Derechos Humanos resuelve la demanda interpuesta por tres ciudadanos griegos que habían sido elegidos diputados por el PASOK y fueron privados de su escaño como consecuencia de una Sentencia del Tribunal Supremo griego que estableció una nueva jurisprudencia sobre la fijación el cociente electoral por la cual los votos en blanco pasarían a computarse para la fijación del cociente electoral. Es relevante para el caso que esta Sentencia del Tribunal Supremo griego sólo se aplicó en este caso controvertido y que el Parlamento griego aprobó seguidamente una modificación de la ley electoral para que no cupiera ninguna duda sobre la interpretación de cómo debía fijarse el cociente electoral que, como se había hecho hasta entonces, debía excluir a los votos en blanco.

55 STEDH de 10 de abril de 2008 (Asunto Paschalidis, Koutmeridis contra Grecia), $\S 332$ y 34 .

56 STEDH de 2 de marzo de 1987 (Asunto Mathieu-Mohin y Clerfayt contra Bélgica), § 54. 
do en la representación proporcional ni impide la existencia de elementos que modulen la proporcionalidad del sistema ${ }^{57}$.

Como ejemplo de lo primero, pueden mencionarse el Asunto Partido Liberal, R. y P. contra Reino Unido ${ }^{58}$ y el Asunto X contra Islandia ${ }^{59}$. En el primero, la Comisión consideró que el sistema electoral británico basado en el principio «first past the post» era un sistema aceptable para las elecciones parlamentarias y no resultaba ilegítimo a pesar del escaso número de escaños que le habían correspondido al Partido Liberal en relación con alto porcentaje del voto nacional obtenido, mientras que en el Asunto X contra Islandia, se obligó a la Comisión a pronunciarse sobre el diferente peso de los votos que se derivaba de la distribución desigual de los escaños entre las circunscripciones y concluyendo ésta que no pueden calificarse arbitrarias las diferencias nacidas de los sistemas electorales, pues se aplican con carácter general a todas las candidaturas, sin favorecer a ningún partido político en particular ni otorgar una situación de ventaja a ningún candidato en detrimento de los demás.

En cuanto a los elementos que modulan la proporcionalidad del sistema electoral, en los Casos Federación Nacionalista Canaria contra España ${ }^{60}$ y Yumak y Sadak contra Turquía ${ }^{61}$ el Tribunal Europeo de Derechos Humanos ha constatado la compatibilidad con el Convenio de la introducción de unas barreas electorales muy elevadas. Lo que demuestra que el Tribunal sigue convencido de que no debe revisar la convencionalidad de los sistemas electorales, demostrándose con ello que el artículo 3 del Protocolo I ofrece una protección menor que

57 STEDH de 2 de marzo de 1987 (Asunto Mathieu-Mohin y Clerfayt contra Bélgica), § 54 y STEDH de 18 de febrero de 1999 (Asunto Matthews contra el Reino Unido), § 64.

58 DECDH de 18 de diciembre de 1980 (Asunto Partido Liberal, R y P contra Reino Unido), demanda n. ${ }^{\circ} 8765 / 79$.

59 DCEDH de 8 de diciembre de 1981 (Asunto X contra Islandia), demanda n. ${ }^{\circ} 8941 / 80$.

60 Decisión del Tribunal Europeo de Derechos Humanos de 7 de junio de 2001 (Asunto Federación Nacionalista Canaria contra España). En esta decisión el Tribunal Europeo de Derechos Humanos inadmite la demanda de la Federación Nacionalista Canaria que no había obtenido ningún escaño en las elecciones autonómicas de 1999, pese haber obtenido en la circunscripción de Lanzarote un $28 \%$ de los sufragios por aplicación de la disposiciones del Estatuto de Autonomía Canario que prevé una barrera electoral del $6 \%$ de los votos validamente emitidos en la Comunidad Autónoma o alternativamente, si ésta no se supera, haber obtenido al menos el $30 \%$ de los votos emitidos en la circunscripción correspondiente que es la isla.

61 SSTEDH de 30 de enero de 2007 (Asunto Yumak y Sadak contra Turquía) y 8 de julio de 2008 (Gran Sala, Asunto Yumak y Sadak contra Turquía). En estas Sentencias, el Tribunal Europeo de Derechos Humanos resuelve la demanda planteada por dos candidatos del Partido Democrático del Pueblo en las elecciones parlamentarias de 2002 que no habían resultado elegidos a pesar de que su candidatura había obtenido el $45,95 \%$ de los votos de su circunscripción pero no había alcanzado el $10 \%$ de los votos a nivel nacional. 
muchas de las legislaciones nacionales en las que, normalmente por la interpretación jurisprudencial del mandato constitucional del principio de igualdad de voto, se permite controlar la actuación del legislador electoral en la distribución de los escaños entre circunscripciones y en la configuración de los distintos elementos del sistema electoral para asegurar, al menos tendencialmente, el mismo peso de los votos e iguales oportunidades de éxito a las candidaturas ${ }^{62}$.

\section{CONDICIONES OBJETIVAS DE EJERCICIO DEL SUFRAGIO ACTIVO}

Para terminar con este análisis de la jurisprudencia del artículo 3 del Protocolo I, nos queda ocuparnos de otros dos requisitos objetivos que impone la letra de este precepto: la periodicidad de las elecciones y el ámbito objetivo de la decisión popular. Respecto al primero de ellos, la regularidad en el pronunciamiento de los ciudadanos se entiende como algo inherente a la propia definición del principio democrático y tiene por objeto garantizar que las ideas de los representantes del pueblo reflejen la evolución de la opinión pública dominante $^{63}$. La temporalización de dichos intervalos queda dentro del margen de apreciación de los Estados, de manera que sólo podrá considerarse vulneración del artículo 3 cuando los comicios se aplacen sine die o bien se sobrepase un lapso de tiempo que exceda los usos normales de los Estados respecto a la periodicidad de las elecciones ${ }^{64}$. Pues, debe tenerse en cuenta que la duración de la legislatura debe permitir al Parlamento la elaboración y puesta en ejecución de los proyectos legislativos y si un intervalo demasiado corto puede impedir las estrategias políticas necesarias para responder a la voluntad del electorado, uno demasiado largo puede conducir a la falta de renovación de la representación parlamentaria y a la desconexión con las aspiraciones del electorado.

62 Sobre la configuración de esta garantía constitucional resulta obligada la consulta de SÁNCHEZ MUÑOZ, O. (1999): «Sistema electoral y principio de igualdad del sufragio», F. Pau I Vall (Coordinador): Parlamento y Sistema electoral, (IV Jornadas de la Asociación de Letrados de Parlamentos), Aranzadi, Pamplona págs. 491-528

63 DCEDH de 11 de septiembre de 1995 (Asunto Jan Timke contra Alemania), demanda n. ${ }^{\circ}$ 27311/1995, sobre la admisibilidad de la demanda presentada por un funcionario alemán que defendía que la ampliación de la duración de la legislatura del Parlamento de la Baja-Sajonia de cuatro a cinco años suponía la vulneración de la obligación de «organizar elecciones a intervalos razonables». La Comisión concluyó que este intervalo no puede considerarse excesivo y permite reflejar correctamente la evolución de la opinión del pueblo.

64 Vid. GARCÍA SORIANO, M. V. (1996): «El artículo 3 del Protocolo Adicional al Convenio de Roma de 1950: análisis del derecho a unas elecciones libres», Cuadernos Constitucionales de la Cátedra Fadrique Furiò Ceriol, núm. 14/15, págs. 215-231, concretamente pág. 223. 
La Comisión tuvo que enfrentarse a esta cuestión en el Asunto Griego, consecuencia del golpe de Estado de los coroneles, que provocó la disolución del Parlamento griego en 1967 sin el establecimiento de la fecha de unas nuevas elecciones. Aunque el Gobierno griego se escudó en la situación de excepcionalidad en la vida de la nación griega, en el hecho de que las elecciones legislativas griegas habían tenido lugar en 1964 y que se celebrarían elecciones tras la aprobación de una la nueva Constitución en 1968. Lo que, a su juicio, supondría reconocer que el intervalo entre los dos periodos electorales era razonable ${ }^{65}$. A la Comisión -y luego al Comité de Ministros que hizo suyos los argumentos de ésta— esta interpretación le parece excesivamente formalista, pues la cláusula «a intervalos razonables» debe interpretarse de acuerdo con el objetivo de la regularidad de las elecciones, que no es otro que asegurar la conexión entre la voluntad popular y la composición del órgano legislativo. Por ello, con buen criterio, declaró que Grecia había incumplido su obligación de organizar elecciones libres a intervalos razonables, puesto que ni siquiera la concurrencia de situaciones extraordinarias puede justificar la suspensión del Parlamento o de las elecciones. El asunto provocó incluso la expulsión de Grecia del Consejo de Europa.

En cuanto al ámbito espacial de las elecciones, el tenor literal del artículo 3 nos remite a las elecciones al Cuerpo Legislativo y nos lleva a preguntarnos si cabría la inclusión de otro tipo de votaciones en las que se exprese la opinión del pueblo. El Tribunal ha realizado una interpretación restrictiva de manera que las garantías derivadas del Convenio no se extienden a todo tipo de comicios, sino sólo a aquellos en las que se elige un órgano representativo con capacidad para «aprobar en su ámbito territorial leyes sobre cuestiones cruciales en una sociedad democrática» ${ }^{66}$. Lo que deja fuera de su ámbito de protección a las elecciones presidenciales y a las consultas populares celebradas por la vía del referéndum.

Así lo ha declarado el Tribunal en asuntos relacionados con los referéndums de adhesión a la Unión Europea ${ }^{67}$ y con la práctica del referéndum abrogativo en

65 DCEDH de 15 de abril de 1970 (Asunto griego), demandas n. ${ }^{\circ} 3321 / 67,3322 / 67$, 3323/67 y 3344/67 y resolución del Comité de Ministros de 26 de noviembre de 1974.

66 STEDH de 1 de julio de 2004 (Asunto Vito Sante Santoro contra Italia). En esta Sentencia, el Tribunal Europeo de Derechos Humanos resuelve la demanda de un ciudadano italiano sometido a la situación de vigilancia especial que, en la legislación italiana conlleva la privación del derecho de sufragio durante el tiempo que dure esta medida preventiva y que, como consecuencia de ello, se había visto privado de la posibilidad de votar en las elecciones regionales de 1995 y en las generales de 1996 y en el referéndum de 11 de junio de 1995.

67 Véanse en este sentido, las Decisiones sobre la admisibilidad de la demanda del Tribunal Europeo de Derechos Humanos (en adelante DTEDH) de 7 de septiembre de 1999 (Asunto Hilbe contra Liechtenstein) relativa la referéndum previsto para el mes de mayo de 1995 sobre la incorporación de Liechtenstein al espacio económico europeo; de 26 de enero de 2000 (Asunto Z 
Italia ${ }^{68}$. Mientras que en relación a las elecciones presidenciales resulta muy interesante el pronunciamiento del Tribunal en el Asunto Paksas contra Lituania en donde, a pesar de declarar que la sorprendente rapidez en la tramitación del procedimiento legislativo que siguió al cese por impeachment de Rolandas Pasksas iba dirigido a impedir la presentación de su candidatura a la Presidencia de la República, no entró en el fondo de esta queja por no tratarse de elecciones legislativas ${ }^{69}$. Se trata de una línea jurisprudencial, iniciada ya por la Comisión ${ }^{70}$, que el Tribunal de Estarsburgo debiera replantearse habida cuenta de la finalidad que persigue este precepto como garante de una concurrencia electoral libre y de la existencia de oposición política, en cuanto elementos imprescindibles de toda democracia. Elementos que son extensibles a todo tipo de consultas dirigidas al electorado.

No obstante, esto no significa que el Tribunal haya reservado el ámbito de aplicación de este artículo a las elecciones generales, de manera que, razonablemente, extiende la garantía a las asambleas legislativas infraestatales e incluso el Par-

contra Letonia), relativa al referéndum de 20 de septiembre de 2003 de adhesión de Letonia a la Unión europea y de 11 de marzo de 2008 (Asunto Niedzwiedz contra Polonia) sobre el referéndum de 8 de junio de 2003 y las elecciones presidenciales de 2001.

68 Véanse DDTEDH Humanos de 20 de junio de 2002 (Asunto Borghi contra Italia), relativa a los referéndums abrogativos de 21 de mayo de 2000; de de 16 de enero de 2003 (Asunto Vito Sante Santoro contra Italia), en la que se declara la indamisibilidad parcial de la demanda sobre la queja relativa a la incapacidad electoral para el referéndum abrogativo de 11 de junio de 1995 y de 8 de julio de 2003 (Asunto Comisión promotora del referéndum mayoritario y Comisión promotora del referéndum antiproporcional contra Italia), relativas a los referéndums de 18 de abril de 1999 y de 21 de mayo de 2000.

69 STEDH de 6 de enero de 2011 (Asunto Paksas contra Lituania), $\S \S 71,72$ y 112 . No obstante si se constató la vulneración del derecho a unas elecciones libres por haberle impedido presentar su candidatura como diputado de la Seimas. Véanse también las DDTEDH de 27 de mayo de 2004, (Asunto Guliyev contra Azerbaiyán), de 2 de septiembre de 2004, (Asunto Boškoski contra la antigua República yugoslava de Macedonia) y de de 11 de marzo de 2008 (Asunto Niedzwiedz contra Polonia) sobre el referéndum de 8 de junio de 2003 y las elecciones presidenciales de 2001.

70 Sobre el referéndum véanse las DDCEDH de 3 de octubre de 1975 (Asunto X contra Reino Unido), sobre el referéndum de adhesión a las Comunidades Europeas; de 15 de mayo de 1996 (Asunto Bader contra Austria), demanda n. ${ }^{\circ}$ 26633/95, relativa al referéndum de 12 de junio de 1994 sobre la adhesión a la Unión europea de Austria; de 26 de febrero de 1997 (Asunto Nurminen y otros contra Finlandia), demanda n. ${ }^{\circ} 27881 / 95$, relativa al referéndum consultivo de 16 de octubre de 1994 de adhesión de Finlandia a la Unión Europea y de 14 de septiembre de 1998 (Asunto Castelli y otros contra Italia), demandas n. ${ }^{\circ} 35790 / 97$ y 38438/97, relativa al referéndum abrogativo de la legislación en materia de financiación pública de los partidos políticos y sobre las elecciones presidenciales la DCEDH de 14 de diciembre de 1982 (Asunto Habsburgo-Lorena contra Austria), demanda n. ${ }^{\circ} 15344 / 89$. 
lamento europeo, pues en definitiva supone aplicar el mismo criterio de decisión: allí donde se da la representación política en corporaciones de base territorial ${ }^{71}$. Por eso el Tribunal opina que la expresión «cuerpo legislativo» debe interpretarse a la vista de la estructura territorial establecida por las Constitución de cada Estado ${ }^{72}$.

Es más, analizando la jurisprudencia de la antigua Comisión y del Tribunal puede apreciarse incluso la propia evolución del modelo territorial en algunos Estados. Así, en los primeros casos de elecciones a Consejos regionales belgas, la Comisión constató que estas Asambleas carecían de funciones legislativas, realizando únicamente funciones reglamentarias, consultivas y de propuesta de legislación ${ }^{73}$. Sin embargo, la reforma constitucional de 1980 atribuyó a los consejos regionales la facultad de emitir decretos con fuerza de ley en determinadas materias sobre las cuales se les ha atribuido expresamente competencia. Por eso, a partir del Asunto Serge Moureaux y otros contra Bélgica, empiezan a admitirse las demandas relacionadas con este órgano legislativo regional ${ }^{74}$.

Otros supuestos en los que el Tribunal ha constado que los Parlamentos de las entidades territoriales forman parte del «Cuerpo legislativo» han sido, por ejemplo, el Consejo Flamenco en Bélgica, los Parlamentos autonómicos en España, el Congreso Regional de Nueva Caledonia en Francia y los Consejos Regionales en los Asuntos Matbieu-Mobin y Clerfayt contra Bélgica ${ }^{75}$, Federación Nacionalista Canaria contra España ${ }^{76}$, Py contra Francia ${ }^{77}$ y Vito Sante Santoro contra Italia ${ }^{78}$.

La misma evolución puede comprobarse en el caso del Parlamento europeo. En el Asunto Matthews contra el Reino Unido ${ }^{79}$, la Gran Sala consideró que las elecciones al Parlamento Europeo debían incluirse también dentro del ámbito de aplicación del precepto. En sus argumentos expone la evolución de las tareas del Parlamento Europeo y, sobre todo, el incremento de sus poderes de decisión

71 GARCÍA ROCA, F. J. (2005): «Del compromiso internacional de los Estados de organizar elecciones libres al derecho de sufragio de los ciudadanos (art. 3 P1)», op. cit., pág. 908.

72 Por todas véase STEDH de 2 de marzo de 1987(Asunto Mathieu-Mohin y Clerfayt contra Bélgica), §53.

73 DCEDH de 30 de mayo de 1975 (Asunto W, X, Y y Z contra Bélgica), demandas n. ${ }^{\circ} 6745 / 74$ y $6746 / 74$.

74 DDCEDH de 12 de julio de 1983 (Asunto Serge Moureax y otros contra Bélgica), demandas n. ${ }^{\circ} 6745 / 74$ y 6746/74 y de 17 de mayo de 1985 (Asunto Georges Clerfayt, Pierre Legros y otros contra Bélgica), demanda n. ${ }^{\circ}$ 10650/83.

75 STEDH de 2 de marzo de 1987(Asunto Mathieu-Mohin y Clerfayt contra Bélgica).

76 Decisión del Tribunal Europeo de Derechos Humanos de 7 de junio de 2001 (Asunto Federación Nacionalista Canaria contra España).

77 STEDH de 11 de enero de 2005 (Asunto Py contra Francia).

78 STEDH de 1 de julio de 2004 (Asunto Vito Sante Santoro contra Italia).

79 STEDH de 18 de febrero de 1999 (Asunto Matthews contra el Reino Unido). 
en el procedimiento legislativo, en el control democrático y de responsabilidad política en el sistema comunitario. Algo que la Comisión había anunciado que podía ocurrir en el Asuntos Kennedy Lindsay y otros contra Reino Unido en los que, pese a constatar que el Parlamento europeo no ejercía poderes legislativos, dejó abierta la vía a su inclusión dentro del ámbito de aplicación del Convenio a medida que los nuevos órganos representativos de las Comunidades europeas fueran asumiendo los poderes y funciones de los cuerpos legislativos nacionales ${ }^{80}$.

Mención aparte merecen las elecciones locales. Tanto la Comisión como el Tribunal han considerado su inclusión dentro del ámbito de aplicación del Convenio como una cuestión no resuelta en las legislaciones nacionales, por lo que o bien como hace con los Parlamentos territoriales, analiza las atribuciones de los órganos representativos municipales o provinciales o bien elude pronunciarse sobre la cuestión porque le resulta menos complicado no admitir la demanda resolviendo sobre una cuestión de fondo sobre la que existe una doctrina consolidada o porque no se lo plantean las partes.

Así, desde sus primeras decisiones la antigua Comisión rechazó que los órganos locales de Irlanda del Norte (que habían sido suspendidos desde 1969), los Consejos municipales en Bélgica y los Consejos Metropolitanos de Condado en el Reino Unido entrasen dentro de la calificación «cuerpo legislativo» a los efectos del artículo 3 del Protocolo I porque carecen de atribuciones legislativas y, en el mejor de los casos, sus competencias normativas se reducían a la aprobación de reglamentos ejecutivos de la ley ${ }^{81}$. El Tribunal también ha aplicado este criterio en muchas de las demandas que se le han presentando ${ }^{82}$, pero nos interesa destacar los asuntos concernientes a España, en los que ha reiterado que los Ayuntamientos no ejercen potestades legislativas ${ }^{83}$.

80 DCEDH de 8 de marzo de 1978 (Asunto Kennedy Lindsay y otros contra Reino Unido), demanda n. ${ }^{\circ} 8364 / 78$. Reiterada en las DDCEDH de 19 de mayo de 1979 (Alianza de los belgas de la Comunidad europea contra Bélgica), demanda n. ${ }^{\circ}$ 8612/79 y de 9 de diciembre de 1987 (Asunto Tete contra Francia), demanda 11123/83.

81 Véase las DDCEDH de 12 de julio de 1976 (Asunto X contra Reino Unido), demanda n. ${ }^{\circ}$ 5155/71; de 17 de mayo de 1985 (Asunto Georges Clerfayt Pierre Legros y otros contra Bélgica), demanda n. ${ }^{\circ}$ 10650/83; de 5 de julio de 1985 (Asunto Booth-Clibborn y otros contra Reino Unido), demanda n. ${ }^{\circ} 11391 / 85$.

82 Por todas pueden verse la STEDH de 1 de julio de 2004 (Asunto Vito Sante Santoro contra Italia), sobre los consejos provinciales italianos y las DDTEDH de 25 de enero de 2000 (Asunto Cherepkov contra Rusia) sobre la elección de los consejos municipales rusos y de 6 de marzo de 2003 (Asunto Zdanoka contra Letonia), sobre la elección del Consejo Municipal de Riga.

83 DDTEDH de 12 de octubre de 2000 (Asunto Salleras Linares contra España); de 30 de junio de 2009 (Asunto Etxebarria y otros contra España) y de 4 de octubre de 2011 (Asunto Méndez Pérez contra España). 


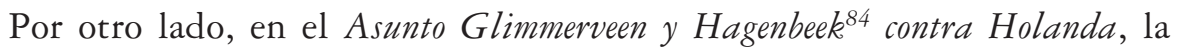
antigua Comisión no llego pronunciarse sobre si el artículo 3 del Protocolo I es aplicable a las elecciones municipales holandesas porque considera que la exclusión de la candidatura por la que se presentaban los demandantes, una asociación que promovía la discriminación racial, es un fin completamente legítimo y acorde con el artículo 17 del CEDH que establece un instrumento de Democracia militante prohibiendo utilizar las disposiciones del Convenio, en este caso el derecho a las elecciones libres, para destruir los derechos y libertades reconocidos en él. Igual forma de proceder nos encontramos en el asunto Luksch contra Italia ${ }^{85}$, en el que, como vimos, un ciudadano alemán residente en Italia se queja de que la legislación le impide participar en las elecciones locales italianas. Como considera que la nacionalidad es un criterio de capacidad electoral comúnmente aceptado por las leyes electorales nacionales, no es necesario debatir si las elecciones locales se encuentran protegidas por el artículo 3 del Protocolo I.

Pero, finalmente, el Tribunal de Estrasburgo, ha aplicado directamente en las elecciones locales el artículo 3 del Protocolo adicional a un candidato a las elecciones municipales que fue excluido indebidamente de las listas en el Asunto Labita contra Italia y a un preso privado del sufragio en las elecciones locales y parlamentarias en el Asunto Hirst contra Reino Unido sin ninguna justificación adicional sobre la extensión del ámbito de aplicación del precepto a las elecciones locales $^{86}$. Y, aunque esta solución nos parece la más adecuada, dada la base representativa de los órganos de gobierno locales, exigiría un pronunciamiento expreso del Tribunal que aclarase de manera definitiva la cuestión.

\section{CONCLUSIÓN}

La interpretación del artículo 3 del Protocolo I realizada por la Comisión y por el Tribunal Europeo de Derechos Humanos ha supuesto el paso de una protección de mínimos, consistente en la obligación de los Estados parte de celebrar elecciones libres y mantenerse así fieles al principio democrático, a una protección equiparable a la de los demás derechos del Convenio al haber ido ampliando el contenido del precepto hasta reconocer derechos subjetivos de participación política: el sufra-

84 DCEDH de 11 de octubre de 1979 (Asunto Glimmerveen y Hagenbeek contra Holanda), demandas n. ${ }^{\circ} 8348 / 78$ y 8406/78.

85 DCEDH de 21 de mayo de 1997 (Asunto Luksch contra Italia), demanda n. ${ }^{\circ}$ 27614/95.

86 STEDH de 6 de abril de 2000 (Asunto Labita contra Italia) y de de 6 de octubre de 2005 (Gran Sala, Asunto Hirst contra Reino Unido). 
gio activo, el sufragio pasivo y el derecho al mandato parlamentario. No obstante, la protección del Convenio no alcanza aún los estándares de protección que otorgan la mayoría de las regulaciones nacionales debido a los siguientes motivos.

En primer lugar, por el reconocimiento en esta materia de un amplio margen de apreciación nacional, lo que lleva al Tribunal a dar un enorme peso a las circunstancias nacionales históricas, sociales y políticas a la hora de analizar las irregularidades electorales y los requisitos establecidos por las legislaciones nacionales para ejercer estos derechos. Aplica así, lo que hemos denominado un test débil en su control, en el que se limita a constatar que no se lesione la esencia del derecho o su efectividad y que las restricciones no sean arbitrarias. Sólo cuando está en riesgo la exclusión social mediante la privación del voto a determinados colectivos que tradicionalmente han sido discriminados (presos o incapaces) o las restricciones a las candidaturas pueden influir en la libre formación de la voluntad de los electores durante el proceso electoral, el Tribunal exige un plus de argumentación destinado a probar la proporcionalidad de la medida limitadora del derecho.

En segundo lugar, porque reduce su ámbito de actuación a las elecciones legislativas, no amparando el ejercicio de derechos de participación política más allá de las tradicionales fórmulas de la Democracia representativa, de manera que ni en las elecciones presidenciales ni en las consultas referendarias puede solicitarse la protección por parte de los órganos del Convenio. Tampoco en el caso de las elecciones locales. $\mathrm{Y}$ aunque hemos encontrado algún pronunciamiento del Tribunal que parece contradecir esta afirmación, lo cierto es que el Tribunal sigue exigiendo el ejercicio de facultades legislativas por parte del órgano representativo elegido.

\section{BIBLIOGRAFÍA}

AKANDJI-KOMBE, J. F.: Positive obligations under the European Convention on Human Rights (2007), Estrasburgo, Consejo de Europa.

BASTIDA FREIJEDO, F. J. (1991): «Elecciones y Estado democrático de derecho», Revista Española de Derecho Constitucional, núm. 32, págs. 115-134.

BÖCKENFÖRDE, E. W. (2000): «La democracia como principio constitucional», Ídem: Estudios sobre el Estado de Derecho y la democracia, Madrid, CEPC.

BURATTI, A. (2012): «El uso de la historia en la jurisprudencia del Tribunal Europeo de Derechos Humanos», Revista de Derecho Constitucional Europeo, núm. 18, (se ha consultado la versión electrónica disponible en http://www.ugr. es/ redce/REDCE18/articulos/13_BURATTI.htm.

FERNÁNDEZ VIVAS, Y. (2007): Igualdad y partidos políticos. Análisis constitucional y comparado de la igualdad de oportunidades de los partidos politicos, Madrid, Congreso de los Diputados. 
GARCÍA PELAYO, M. (1986): El Estado de partidos, Madrid, Alianza.

GARCÍA ROCA, F. J. (2005): «Del compromiso internacional de los Estados de organizar elecciones libres al derecho de sufragio de los ciudadanos (art. 3 P1)», en Santolaya Machetti, P. y García Roca, F.J. (Coords.): La Europa de los Derechos: el Convenio Europeo de Derechos Humanos, Madrid, CEPC, págs. 825-854.

GARCÍA SORIANO, M. V. (1996): «El artículo 3 del Protocolo Adicional al Convenio de Roma de 1950: análisis del derecho a unas elecciones libres», Cuadernos Constitucionales de la Cátedra Fadrique Furiò Ceriol, núm. 14/15, págs. 215-231.

GOLUBOK, S. (2009): «Right to free elections: Emerging guarantees or two layers of protection?», Netherlands Quarterly of Human Rights, núm. 27, págs. 361-390.

GOY, RAYMOND (1986): «La garantie européenne du droit à de libres élections législatives: l'article 3 du premier Protocole additionnel à la Convention de Rome», Revue du Droit Public, núm. 5, págs. 1275-1326.

MACKENZIE, W. J. M (1962): Elecciones libres, Madrid, Tecnos.

MOWBRAY, A. (2004): The development of positive obligations under the European Convention on Human Rights by the European Court of Human Rights, Oxford, Portland.

PRESNO LINERA, M. A. (2003): El derecho de voto, Madrid, Tecnos.

SÁNCHEZ MUÑOZ, O. (1999): «Sistema electoral y principio de igualdad del sufragio», F. Pau I Vall (Coordinador): Parlamento y Sistema electoral, (IV Jornadas de la Asociación de Letrados de Parlamentos), Aranzadi, Pamplona págs. 491-528.

- (2007): La igualdad de oportunidades en las competiciones electorales, Madrid, CEPC.

VASEL, J. J. (2009): «El "margin of appreciation" como elemento clave en el Derecho Constitucional Europeo», Revista de Derecho Constitucional Europeo, núm. 11, págs. 189-208.

Title:

DEMARCATION OF THE RIGHT TO VOTE BY EUROPEAN COURT OF HUMAN RIGHTS

\section{Resumen:}

Este artículo analiza la jurisprudencia del Tribunal Europeo de Derechos Humanos sobre el sufragio activo (artículo 3 del Protocolo I). Para ello, partimos de la consideración de que en este derecho debe reconocerse además de una dimensión subjetiva, que define la posición jurídica de los ciudadanos en su relación con los poderes públicos y se concreta en los principios de sufragio universal, libre e igual, una dimensión objetiva en tanto que elemento esencial del Estado Democrático, lo que origina una obligación positiva de los poderes públicos para la realización de su contenido: la libre expresión del pueblo en 
las elecciones del cuerpo legislativo. Sin embargo, el desarrollo de las obligaciones positivas del Estado no ha agotado todas sus posibilidades de manera que el Tribunal Europeo de Derechos Humanos reconoce un amplio margen de apreciación de los Estados en la definición de los sistemas electorales y de las normas del procedimiento electoral.

\title{
Palabras clave:
}

Dimensiones subjetiva y objetiva del sufragio activo; Tribunal Europeo de Derechos Humanos; Obligaciones positivas; Contenido esencial de los derechos fundamentales; Democracia.

\section{Summary:}

I. INTRODUCTION. II. THE INTERSTATE APPEARANCE OF THE ARTICLE 3 PROTOCOL I AND SUBJECTIVE FACULTIES OF THE CONTENT OF THE RIGHT. III. UNIVERSAL SUFFRAGE. IV. FREE VOTE. V. EQUAL VOTE. VI. OBJECTIVE CONDITIONS FOR THE EXERCISE OF ACTIVE SUFFRAGE. VII. CONCLUSION. BIBLIOGRAPHY.

\begin{abstract}
:
This article analyzes the European Court of Humans Rights' jurisprudence on right to vote (article 3 of Protocol n. ${ }^{\circ} \mathrm{I}$ ). For this purpose, it must be acknowledged a subjective dimension too which defines the legal status of citizen in its relations with the public authorities that can be specified in the principle of universal, equal and free suffrage, an objective dimension as an structural element of Democracy and what creates positive obligations to public authorities in order to implement the content of the right: «to ensure the free expression of the opinion of the people in the choice of the legislature». However, the development of positive obligations on the basis of Article 3 of Protocol No. 1 goes no further than this. So, the Court considers that this provision does not require the States to implement a specific electoral system or electoral rules because the State enjoys a wide margin of appreciation when assessing restrictions of these rights.
\end{abstract}

\section{Key Words:}

Subjective and objective dimensions of right to vote.

European Court of Human Rights.

Positive obligations.

Essential content of fundamental rights.

Democracy. 